\title{
Strength Studies on Different Grades of Concrete Considering Fire Exposure
}

\author{
Kiran Kumar Poloju, Ram Kishore Manchiryal, Chiranjeevi Rahul
}

Department of Civil Engineering, Middle East College, Muscat, Oman

Email address:

kpoloju@mec.edu.om (K. K. Poloju), ramkishore@mec.edu.om (R. K. Manchiryal), rahul@mec.edu.om (C. Rahul)

\section{To cite this article:}

Kiran Kumar Poloju, Ram Kishore Manchiryal, Chiranjeevi Rahul. Strength Studies on Different Grades of Concrete Considering Fire Exposure. American Journal of Civil Engineering. Vol. 6, No. 1, 2018, pp. 16-23. doi: 10.11648/j.ajce.20180601.14

Received: November 7, 2017; Accepted: November 16, 2017; Published: December 14, 2017

\begin{abstract}
Concrete is generally strong in compression and weak in tension also it resist against fire. Cement concrete is a complex mixture of different materials, for which the properties may alter in different environmental conditions. The behavior of concrete is depends on difference in temperatures and its mix proportions. The principle effects in the concrete due to elevated temperatures are loss in compressive strength, loss in weight or mass, change in color and spalling of concrete. The objective of this research attempt was to prove experimentally the effects on the behavior of concrete under elevated temperatures of different grades (M20, M40 and M60) of concrete. The compressive strength was determined at different temperatures, thus providing scope of determining loss in strength. In addition, effects on strength under cooling for different grades of concrete were studied. The specimens were kept in oven at certain temperatures $\left(200^{\circ} \mathrm{C}, 400^{\circ} \mathrm{C}, 600^{\circ} \mathrm{C}\right.$, and $\left.800^{\circ} \mathrm{C}\right)$ for 1 hour at constant temperatures. Non-destructive testing (NDT) methods, i.e. Rebound hammer test was adopted to study the changes in surface hardness of concrete specimens subjected to elevated temperatures.
\end{abstract}

Keywords: Grades of Concrete, Mechanical Properties, Elevated Temperatures, NDT, Rebound Hammer Test, Cooling Regime, Water Quenching

\section{Introduction}

Concrete is important material used in any type of construction. Properties of concrete are changes in case of unexpected fire. Hence, it is important to understand the change in the concrete properties in different temperature exposures. As the concrete used for special purpose, the risk of exposing it to high temperature also increases. To be able to predict the response of structure after exposure to high temperature, it is essential that the mechanical properties of concrete subjected to high temperatures be clearly understood. Generally high temperature in the construction can lead to development of cracks. These cracks like any other cracks propagation may eventually cause loss of structural integrity and shorting the life span of structure. The effect of elevated temperatures on mechanical properties of concrete is of very much important for fire resistance studies. Concrete is widely used as structural material in building construction. Where fire resistance is one of the key considerations while designing. Over the last three decades, there have been significant research and development activity in concrete technology and this is has led to improved concrete mixes known as high performance concrete (HPC). These HPC mixes include high strength concrete (HSC), fibre reinforced concrete (FRC), Self-Compacting Concrete (SCC) and fly ash concrete (FAC) which offer superior strength, durability and cost advantages. Thermal properties include thermal conductivity, specific heat, thermal diffusivity, thermal expansion, and mass loss. At this stage it is important to understand the behaviour of concrete at different temperatures. Generally compressive strength will be higher for high strength concrete. Which is made by lowering the water cement ratio to as low as 0.3 resulted with increase in strength and modulus of elasticity of the concrete. The ingredients of high strength concrete are the same as those used in conventional concrete with the addition of one or two admixture, both chemical and mineral. Acceptance of concrete as a main construction material by the construction industry contributed to the economical construction of high-rise buildings and long spans bridges all over world due to its high compression resistance and good durability. In this modern technology construction of high strength concrete is became possible, which unavoidably leads 
to a lower toughness. This causes concrete to fail very suddenly and even explosively. The risk of exposing high strength concrete structures to elevated temperatures increases with the increase in usage of high strength concrete by the construction industry. These studies provides very use full information for the design of special concrete structures sustaining various high temperatures such as nuclear reactor structures, the chemical industry and fire protection. The behaviour of concrete under fire is depends on its mix proportions and constituents and it's determined by complex physiochemical transformations during heating. Failure could occur from the loss of bending or tensile strength, loss of bond strength, loss of shear and torsion strength, loss of compressive strength, and Spalling of concrete. In fact the tensile strength of concrete has a tendency to decrease faster with the temperature than the compressive strength. Concrete is said to have a high degree of fire resistance and in the majority of applications, concrete can be described as virtually fire resistant. When concrete exposed to fire in a building it does not burn or set on fire like other materials also it does not emit any toxic fumes. It will not produce smoke or drip molten particles, unlike some plastic and metals, so it does not add to the fire load. This is due to presence of constituent materials (cement and aggregate) which, when chemically combined with concrete, form a material that is essentially inert and, importantly for fire safety design, has a relatively poor thermal conductivity. It is this slow rate of heat transfer (conductivity) that enable concrete to act as an effective fire shield not only between adjacent spaces, but also to protect itself from fire damage. [1] In their research investigation they replaced OPC with $10 \%, 20 \%$ and $30 \%$ silica fume and resulted that weight and compressive strength of concrete is increased at $600^{\circ} \mathrm{C}$. The heat treatment temperature varied from 100 to $600^{\circ} \mathrm{C}$ for three hours without load. The specimens were heated under similar conditions for each temperature level. All specimens were moist cured for 28 days after casting. [2] studied the influence of test conditions, value of $w / c$ and the presence of silica fume on the compressive strength and elastic modulus of high strength concrete exposed to elevated temperatures and concluded that losses in relative strength due to high temperature exposure were affected by the test condition and $\mathrm{w} / \mathrm{c}$, but the presence of silica fume does not appear to have a significant effect. [3] Studied on the effects of high temperature up to $232^{\circ} \mathrm{C}$ and high pressure up to $13.8 \mathrm{Mpa}$ on the strength of concrete containing various levels of high calcium lignite fly ash and a fixed percentage of condensed silica fumes. It was reported that the decrease in strength was due to the gradual deterioration of the binding matrix with a rise in temperature. [4] Carried out investigations to assess the influence of material and environmental factors on the compressive strength of unsealed cement paste and concrete at high temperatures and found that both material and environmental factors were influencing the strength of concrete during the heat cycle and after cooling. It was reported that the hot strength was greater than the residual strength for a given test temperature. [5] Carried out investigations to study the effect of transient high temperatures on compressive strength of high strength concrete under both unloaded and preloaded conditions and to compare the behaviour with that of normal strength concrete. Based on the results obtained in the study it was concluded that when exposed to temperatures in the range of 100 to $300^{\circ} \mathrm{C}$. [6] Performed fire tests on slab specimens with high strength concrete with and without silica fume and normal strength concrete and concluded that fire endurances of all five specimens were not significantly different. [7] Concrete specimens were heated in a muffle furnace to varying temperatures up to $800^{\circ} \mathrm{C}$ and the changes in the compressive strength, ultrasonic pulse velocity and rebound number were determined. The residual compressive strength for high strength concrete with blended cement after heating to $800^{\circ} \mathrm{C}$ and water quenched, were $31 \%$ of its initial strength whereas they corresponding residual strength for concrete with ordinary Portland cement was 44\%. [6] Conducted research to study the effect of elevated temperature effects on high Strength Concrete residual strength. They concluded that there appeared to be a slight improvement in residual strength at $200^{\circ} \mathrm{C}$ exposure than when it is subjected to $100^{\circ} \mathrm{C}$ exposures. At constant temperatures of $300^{\circ} \mathrm{C}$ there is a significant loss of strength. At temperatures $900^{\circ} \mathrm{C}$ and after, all the concretes essentially had no structural integrity. Residual strengths of $\mathrm{HSC}$ at exposed temperatures of $300^{\circ} \mathrm{C}$ or higher are significantly different than residual strengths for NSC. [14] Experimentally investigated and proved that adding of Nano silica with cement helps in improving strength and durability properties of concrete. In his studies nano silica is added to concrete with different replacements $(1 \%, 1.5 \%$ and $2 \%)$ and found out strength and few durability properties and concluded nano silica with $1.5 \%$ is optimum. [15] Their studies on usage of paper industry waste in concrete was tested as an alternative to traditional concrete. The cement has been replaced by paper industry waste in different replacement levels like $0 \%, 10 \%, 20 \%$, and $30 \%$ by weight for $\mathrm{M}-25$ grade of concrete and found out strength properties. Also concluded that compressive strength was improved with $30 \%$ replacement of cement. [16] In their studies, they provides a summary of findings on the fire response of fibre. Namely, the information on steel fibre reinforced concrete (SFRC), synthetic fibre reinforced concrete and hybrid (steel + synthetic) fibre reinforced concrete have been gathered from various contributions published up to date. The mechanical properties including the melting point and ignition point of fibres affect significantly the properties of concrete composites with addition of fibres.

\section{Materials Used in Present Investigation}

The different materials used in the investigation are

Cement-Cement used in the investigation was 53 Grade Ordinary Portland cement (OPC). The cement was obtained from a single consignment and of the same grade and same source. Procuring the cement it was stored properly. The specific gravity of the cement is found to be 3.11 .

Fine Aggregate-The fine aggregate conforming to zone 2. 
The fine aggregate used was obtained from nearby river source. The bulk density, specific gravity of sand used was $1.56 \mathrm{~g} / \mathrm{cc}$ and 2.65 . The sand used in the present Investigation is passed from $4.75 \mathrm{~mm}$ sieve.

Coarse aggregate-The coarse aggregate used in present investigation is of $20 \mathrm{~mm} \& 10 \mathrm{~mm}$. and brought from a local crushing unit having $20 \mathrm{~mm}$ nominal size. To obtain a well graded aggregate, $85 \%$ of coarse aggregate passing through $20 \mathrm{~mm}$ size and retained on $12.5 \mathrm{~mm}$ sieve was added to $15 \%$ of coarse aggregate passing through $25 \mathrm{~mm}$ sieve and retained on $20 \mathrm{~mm}$ sieve. The specific gravity of coarse aggregate obtained is 2.65 .

Water-Potable water was used in the experimental work for both mixing and curing.

Super plasticizer-In the present work water reducing admixture Conplast SP430 is used. This greatly improves cement dispersion. Conplast SP430 combines the properties of water reduction and workability retention. It allows the production of high performance concrete and concrete with high workability

\section{Experimental Program}

The aim of the experimental study is to compare the compressive strength of normal concrete and high strength concrete of M20, M40, and M60 grade with different temperatures and different cooling regimes. Total number of 120 cubes casted, 40 cubes for M 20, M 40 and M 60 respectively and tested for different sets of temperatures, for a time interval of $60 \mathrm{~min}$, with different modes of cooling which are shown in Table 1.

Table 1. Experimental Program.

\begin{tabular}{|c|c|c|c|c|c|}
\hline Grade of concrete & Temp $\left({ }^{\circ} \mathrm{C}\right)$ & $\begin{array}{l}\text { No. of specimens (Air } \\
\text { cooling) }\end{array}$ & $\begin{array}{l}\text { No. of specimens } \\
\text { (Water quenching) }\end{array}$ & $\begin{array}{l}\text { No. of specimens (Hot } \\
\text { state) }\end{array}$ & No. of specimens \\
\hline \multirow{5}{*}{ M 20} & & & & & 3 \\
\hline & 200 & 3 & 3 & 3 & \\
\hline & 400 & 3 & 3 & 3 & \\
\hline & 600 & 3 & 3 & 3 & \\
\hline & 800 & 3 & 3 & 3 & \\
\hline \multirow{5}{*}{ M 40} & & & & & 3 \\
\hline & 200 & 3 & 3 & 3 & \\
\hline & 400 & 3 & 3 & 3 & \\
\hline & 600 & 3 & 3 & 3 & \\
\hline & 800 & 3 & 3 & 3 & \\
\hline \multirow{5}{*}{ M 60} & & & & & 3 \\
\hline & 200 & 3 & 3 & 3 & \\
\hline & 400 & 3 & 3 & 3 & \\
\hline & 600 & 3 & 3 & 3 & \\
\hline & 800 & 3 & 3 & 3 & \\
\hline
\end{tabular}

The tests conducted on fresh concrete like slump test as per IS: 1199-1959 and compacting factor as per IS: 1199-1959 to determine workability and tests on hardened concrete to check the quality of concrete. The entire casting was done in three stages to M20, M40 and M60 grades of concrete. A pan mixer having $100 \mathrm{~kg}$ capacity was used for mixing concrete. In case of HSC of M60 grade superplasticizer was used for workability purpose as per the specification and calculations. After the completion of casting all the specimens were kept to maintain the ambient conditions viz. temperature of $35 \pm 2{ }^{\circ} \mathrm{C}$ and $90 \%$ relative humidity for $24 \mathrm{hrs}$. The specimens were removed from the mould and submerged in clean fresh water until just prior to testing. The electric furnace is used to heat the specimens. The maximum temperature attained in this furnace is $1200^{\circ} \mathrm{C}$. The inner depth of furnace is $120 \mathrm{~mm}$. Initially the furnace is heated to the required temperature by switching on it and when the required temperature is attained then 2 specimens of size $100 \times 100 \times 100 \mathrm{~mm}$ put inside, with door closed tightly, so that no air enters inside the furnace. The specimens were kept for duration of 1 hour inside the furnace and later 4 specimens were quenched in water for rabid cooling and other 4 specimens were kept aside for atmospheric time. The 4 specimens which were quenched in water are removed after 1 hour. Each time 2 specimens were kept at temperatures of $200^{\circ} \mathrm{C}, 400^{\circ} \mathrm{C}, 600^{\circ} \mathrm{C}$ and $800^{\circ} \mathrm{C}$ and the same is repeated and tests like Destructive and Nondestructive tests are conducted on hardened concrete. In non-destructive tests, The Schmidt rebound hammer is used for conducting NDT. The rebound distance is measured on an arbitrary scale marked from 10 to 100 . The rebound distance is recorded as a rebound number corresponding to the position of the rider on the scale. The sample is not destroyed and this test is very useful in determining the strength of existing buildings or structures whereas in destructive test the cube specimens were tested on Tinus Olsen Testing machine of capacity $2000 \mathrm{KN}$. The bearing surface of the machine was wiped off clean and any loose sand and other material removed from the surface of the specimen. The specimen was placed in the machine in such a manner that the load was applied to opposite sides of the cubes as casted i. e., not top and bottom surfaces. The axis of the specimen was carefully aligned at the centre of the loading frame. The load applied was increased continuously at a constant rate until the resistance of the specimen to the increasing load breaks down and no longer can be sustained. The maximum load applied on the specimen was recorded. Before undergoing destructive and non-destructive tests all the specimens were heated at temperatures of $200^{\circ} \mathrm{C}, 400^{\circ} \mathrm{C}, 600^{\circ} \mathrm{C}$ and $800^{\circ} \mathrm{C}$ respectively 
with the help of an electrical furnace for duration of $60 \mathrm{~min}$.

\section{Mix Proportions}

The mix design is prepared for M 20, M 40 and M 60 grade of concrete according to recommendation of IS 456-2000 code book and presented in Table 2 .

Table 2. Mix proportions of materials.

\begin{tabular}{ll}
\hline Grade of concrete & Mix Proportions \\
\hline M 20 & $1: 1.86: 3.14: 0.45$ \\
M 40 & $1: 1.12: 2.78: 0.35$ \\
M 60 & $1: 1.21: 2.85: 0.32$ \\
\hline
\end{tabular}

\section{Results}

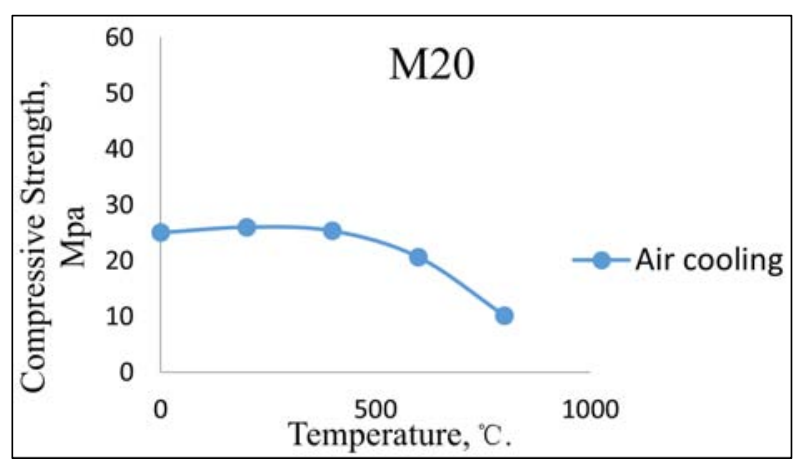

Figure 1. Compressive Strength vs Temperature for M20 grade Air cooling.

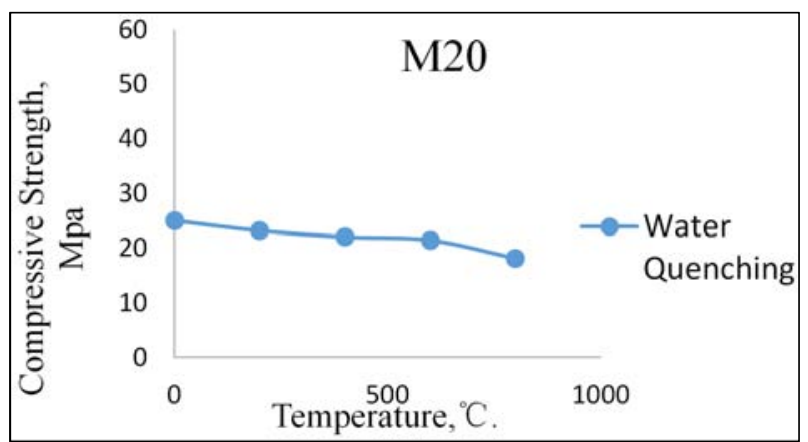

Figure 2. Compressive Strength vs Temperature for M20 grade Water Quenching.

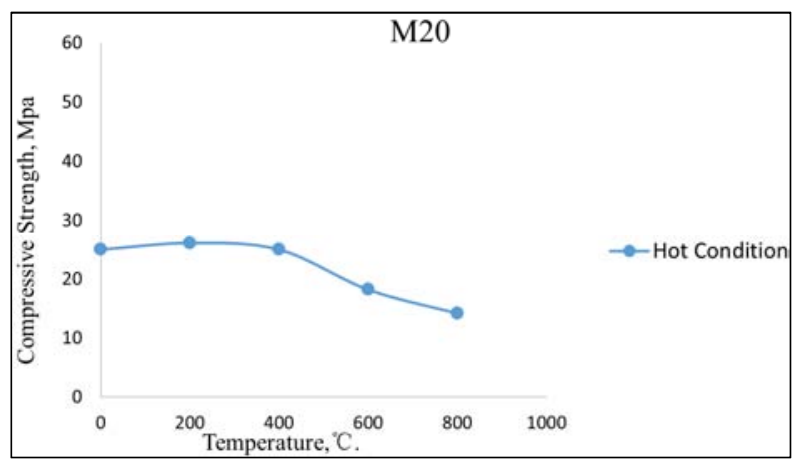

Figure 3. Compressive Strength vs Temperature for M20 grade Hot Condition.

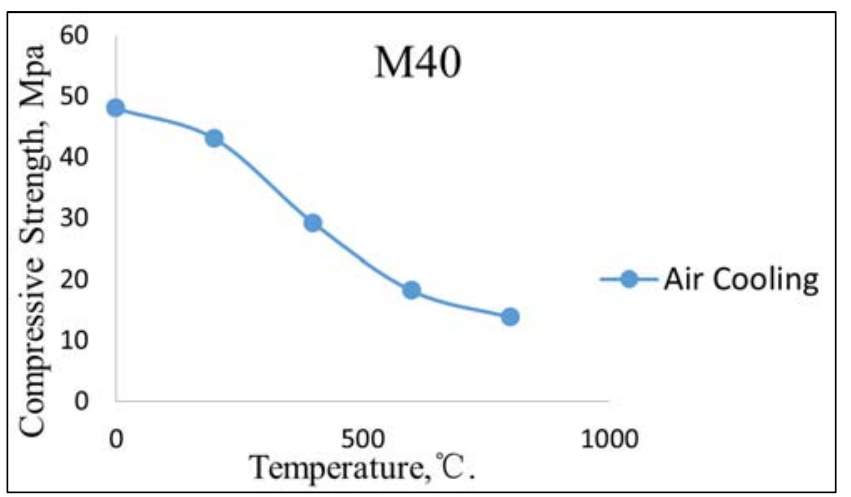

Figure 4. Compressive Strength vs Temperature for M40 grade Air cooling.

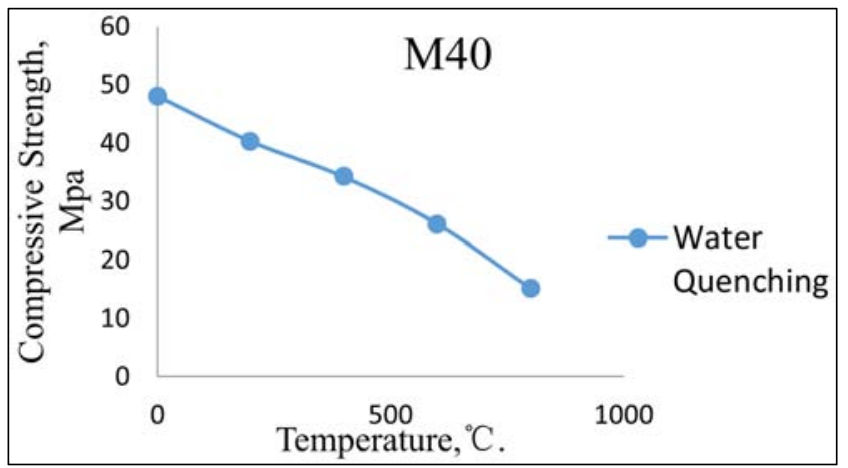

Figure 5. Compressive Strength vs Temperature for M40 grade Water Quenching.

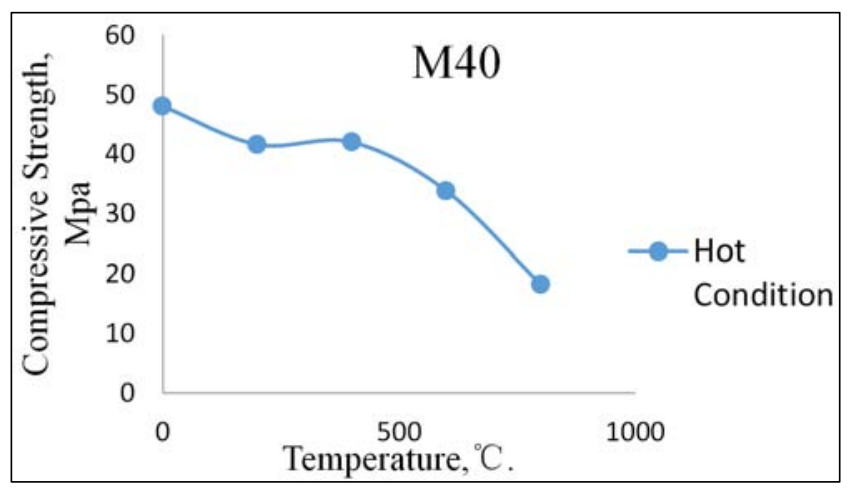

Figure 6. Compressive Strength vs Temperature for M40 grade Hot Condition.

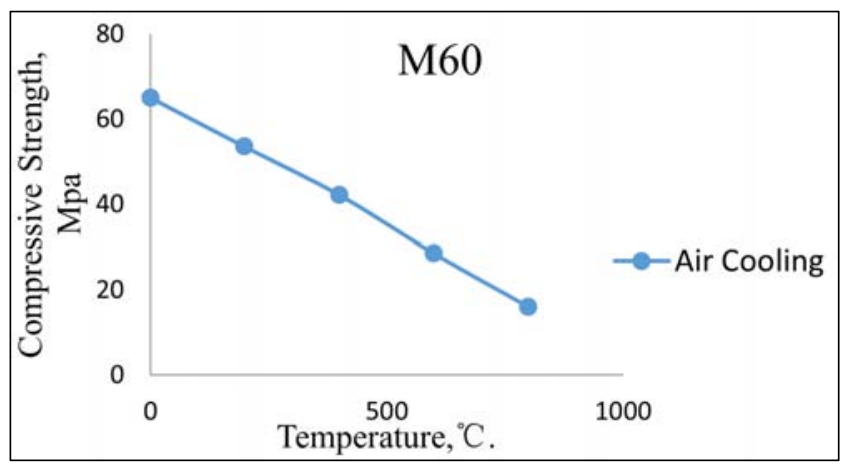

Figure 7. Compressive Strength vs Temperature for M60 grade Air Cooling. 


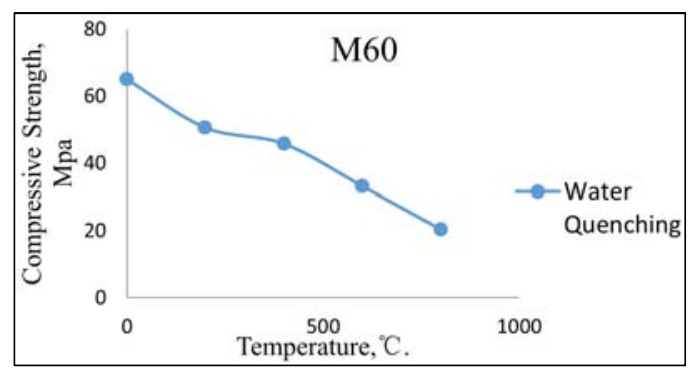

Figure 8. Compressive Strength vs Temperature for M60 grade Water Quenching.

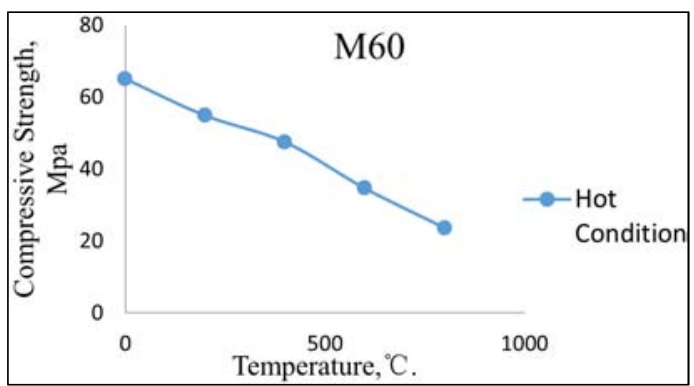

Figure 9. Compressive Strength vs Temperature for M60 grade Hot Condition.

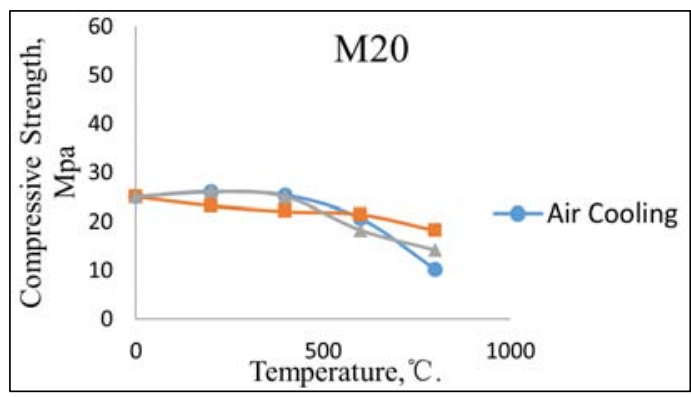

Figure 10. Compressive Strength vs Temperature for M20 grade.

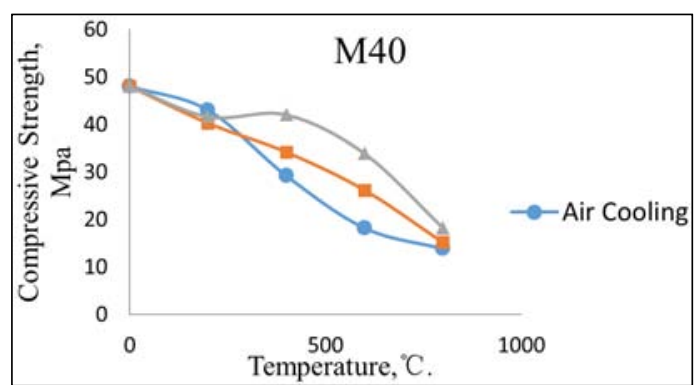

Figure 11. Compressive Strength vs Temperature for M40 grade.

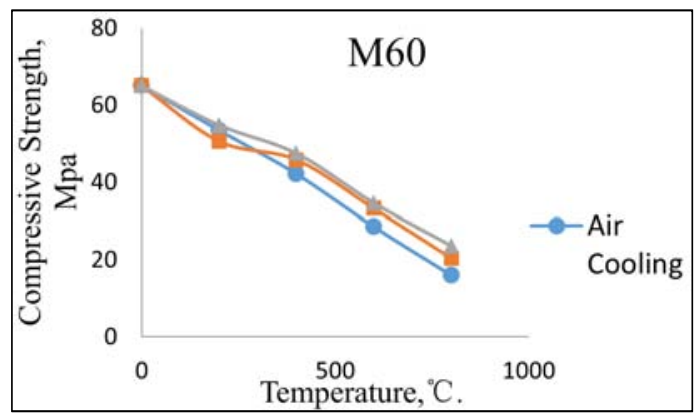

Figure 12. Compressive Strength vs Temperature for M60 grade.

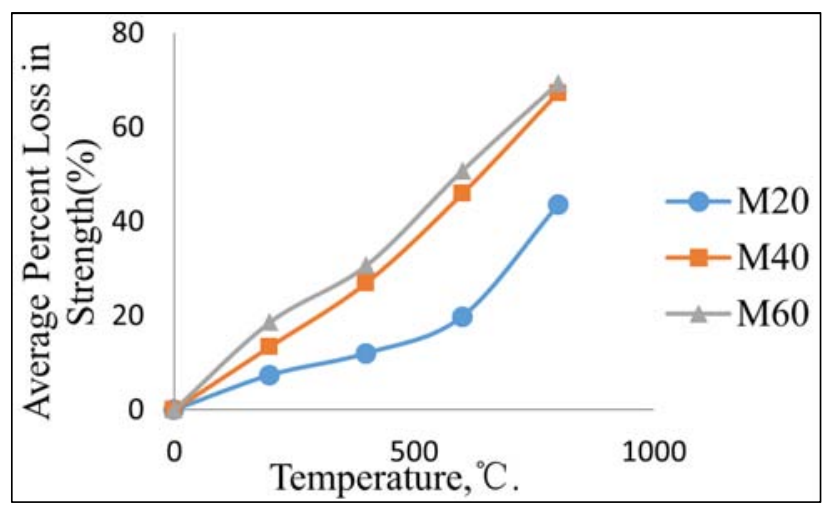

Figure 13. Percent loss in Strength vs temperature.

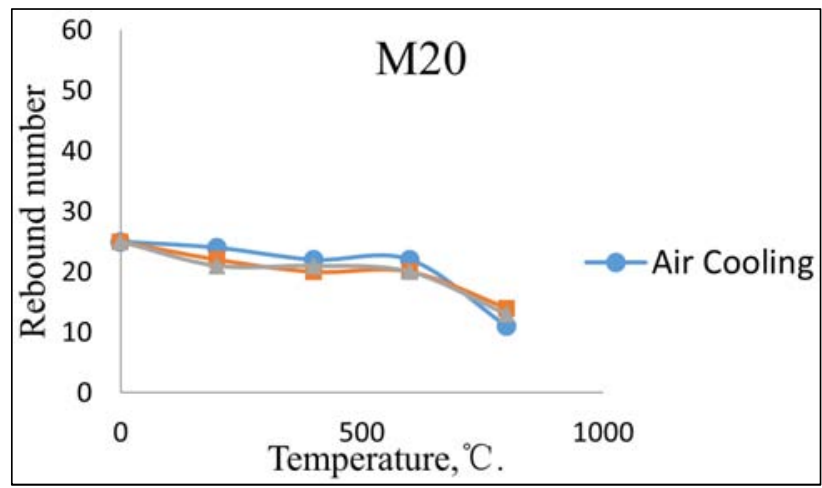

Figure 14. Rebound number vs temperature for M20 grade.

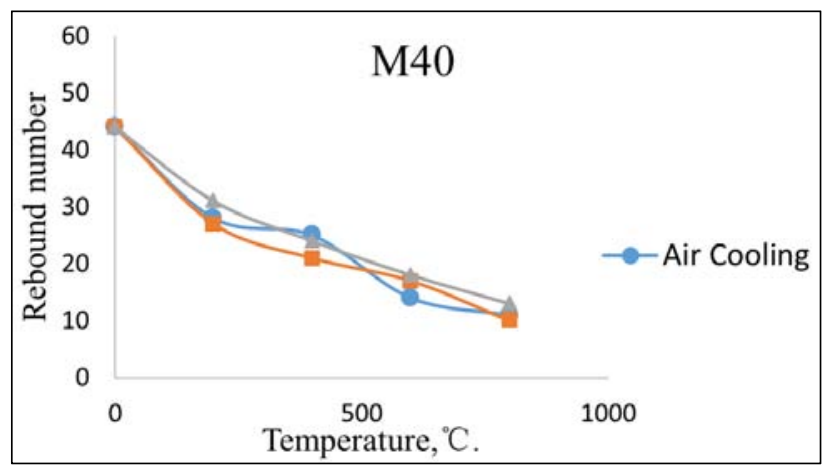

Figure 15. Rebound number vs Temperature for M40 grade.

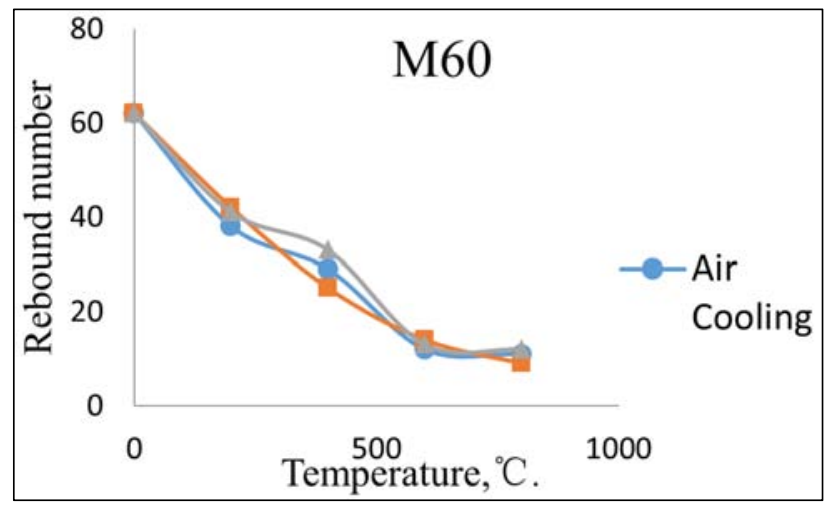

Figure 16. Rebound number vs Temperature for M60 grade. 


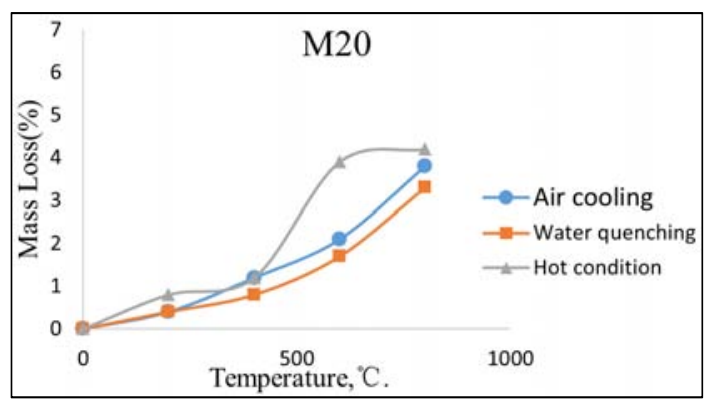

Figure 17. Mass loss vs Temperature for M20 grade.

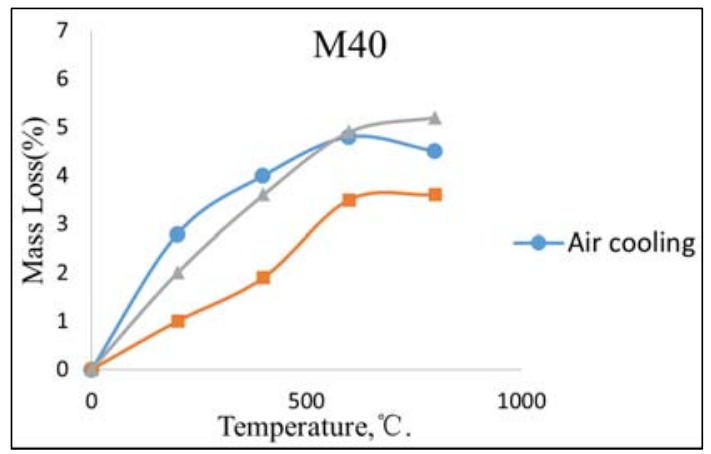

Figure 18. Mass loss vs Temperature for M40 grade.

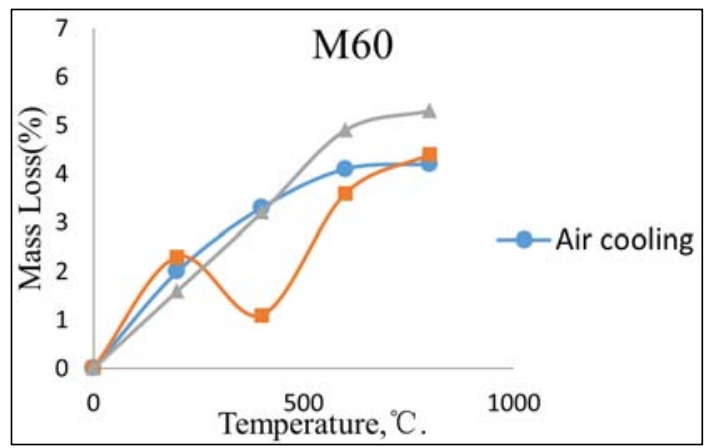

Figure 19. Mass loss vs Temperature for M60 grade.

\section{Analysis and Discussion of Results}

In the present investigation the study of the compressive strength behavior of the normal concrete and high strength concrete has been carried out. The discussions of test results on the following aspects are presented

1. Effect of elevated temperature on compressive strength of concrete

2. Effect of cooling regime on compressive strength of concrete

3. Effect of elevated temperature on surface characteristics of concrete

\subsection{Observations}

It was observed that the magnitude and extent of cracking was more in case of high strength concrete compared to normal concrete. At high temperatures of exposure there is an effect on dimensional stability of the specimens, the sharp edges of the specimen become blunt. Both Normal and High strength concrete specimens when they are subjected to elevated temperatures a small surface cracks were observed. The magnitude and extent of cracks were somewhat negligible up to $400^{\circ} \mathrm{C}$. As the temperature goes above $400^{\circ} \mathrm{C}$ the magnitude and extent of cracks has increased for both normal and high strength concrete. $\mathrm{Up}$ to $600^{\circ} \mathrm{C}$, the failure pattern of concrete cubes was found to be similar to that of control concrete. The cubes were found to have got crushed into small pieces and explosive spalling was observed at $800^{\circ} \mathrm{C}$. A colour change of (light pink) surface of the specimen has been observed at $600^{\circ} \mathrm{C}$. The concrete after exposure to $800^{\circ} \mathrm{C}$ was found to be red hot and concrete looked slightly pink even after cooling. The change of colour may be due to the desiccation of water from the surface of the concrete specimen.

\subsection{Effect of Elevated Temperatures on Type of Concrete}

The compressive strength results of Normal concrete and high strength concrete subjected to different exposure of temperature. Clearly indicate that there is a reduction in compressive strength with temperatures of exposure. The reduction in compressive strength with temperature occurred both normal concrete and high strength concrete. The variation in the compressive strength of NC and HSC with temperature indicates a nonlinear variation.

The average loss in strength in $\mathrm{NC}$ is about $7.4 \%, 12 \%$, $19.8 \%$, and $43.5 \%$ at $200^{\circ} \mathrm{C}, 400^{\circ} \mathrm{C}, 600^{\circ} \mathrm{C}$, and $800^{\circ} \mathrm{C}$ respectively. In case of HSC the average compressive strength loss is observed to be $18.6 \%, 30.6 \%, 50.7 \%$, and $69.3 \%$ at $200^{\circ} \mathrm{C}, 400^{\circ} \mathrm{C}, 600^{\circ} \mathrm{C}$, and $800^{\circ} \mathrm{C}$ respectively. In general the HSC mixers normally have high paste to aggregate content compared to NC. Hence more loss of strength in HSC may be attributed to be occurrence of micro cracking because of thermal incompatibility of hardened cement past and aggregates. Compressive strength loss in High Strength Concrete is seen more than the ordinary concrete because of the quantity of cement required is about $5-20 \%$ less than that of ordinary concrete as shown in Figure 20 and as shown in Figure 21 .

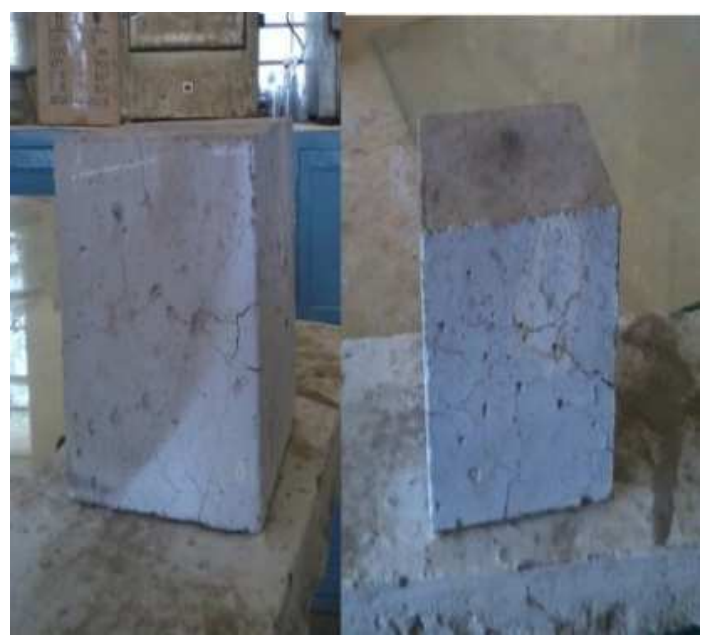

Figure 20. Concrete specimens subjected to $800^{\circ} \mathrm{C}$. 


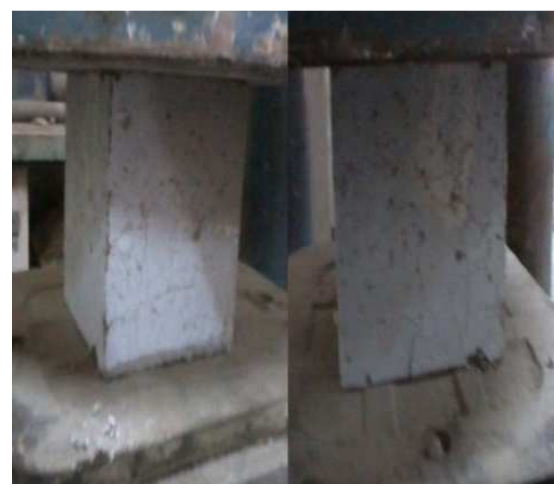

Figure 21. Concrete specimens subjected to $400^{\circ} \mathrm{C}$ and $600^{\circ} \mathrm{C}$.

\subsection{Effect of Elevated Temperature on Grade of Concrete}

The compressive strength test results shows that percent loss of strength with elevated temperatures has increased with increasing grade of concrete. The M40 grade concrete shows higher percent loss than M20 grade concrete. In M20 grade normal concrete the percent of strength loss is about $7.4 \%$, $12 \%, 19.8 \%$, and $43.5 \%$ at $200^{\circ} \mathrm{C}, 400^{\circ} \mathrm{C}, 600^{\circ} \mathrm{C}$, and $800^{\circ} \mathrm{C}$ respectively and shown in Figure 10 . Whereas similar concrete of M40 grade has shown a percent loss in strength of $13.4 \%, 26.9 \%, 45.8 \%$, and $63.8 \%$ at $200^{\circ} \mathrm{C}, 400^{\circ} \mathrm{C}, 600^{\circ} \mathrm{C}$, and $800^{\circ} \mathrm{C}$ respectively and shown in Figure 11.

In case of HSC of M60 Grade the percent loss in strength is about $18.6 \%, 30.6 \%, 50.7 \%$, and $69.3 \%$ at $200^{\circ} \mathrm{C}, 400^{\circ} \mathrm{C}$, $600^{\circ} \mathrm{C}$, and $800^{\circ} \mathrm{C}$ respectively and shown in Figure 12.

Hence high strength concretes have high percent of strength loss than lower strength concretes; however this difference becomes somewhat less significance at temperatures above $600^{\circ} \mathrm{C}$ as shown in Figure 13.

In case of M20 grade concrete the increased in strength was observed at $400^{\circ} \mathrm{C}$, there may be intensifying hydration with temperature to $400^{\circ} \mathrm{C}$. This process is similar to the strength increase behaviour normally observed in steam curing. The increasing content of hydration products occurring in temperature range $100-300^{\circ} \mathrm{C}$ (note that the bound water starts to be released at $180^{\circ} \mathrm{C}$ ) leads to an increase of compressive strength.

\subsection{Effect of Cooling Regime on Compressive Strength of Concrete}

In this investigation the specimen are tested at

1. Room temperature $\left(<40^{\circ} \mathrm{C}\right)$

2. Air Cooling

3. Water Quenching

4. Hot State

The compressive strength reveals that testing after air cooling of specimens resulted in more loss of strength followed by testing after water quenching and testing at hot condition.

In case of normal concrete (M20) subjected to $600^{\circ} \mathrm{C}$ the percent loss in strength observed to be $14.4 \%, 17.6 \%$, and $27.2 \%$ for the cooling regime water quenching, air cooling and hot state and presented in Figure 1, Figure 2 and Figure 3
In case of normal concrete (M40) subjected to $600^{\circ} \mathrm{C}$ the percent loss in strength observed to be $29.6 \%, 45.6 \%$, and $62.2 \%$ for the cooling regime hot state, water quenching and air cooling and presented in Figure 4, Figure 5 and Figure 6

In case of High strength concrete (M60) subjected to $600^{\circ} \mathrm{C}$ the percent loss in strength observed to be $46.8 \%, 49 \%, 56.2 \%$ for the cooling regime hot state, water quenching and air cooling and shown in Figure 7, Figure 8 and Figure 9.

However again at high temperatures of exposure the difference in percent loss in strength between different cooling regime reduces, For example for M40 grade subjected to $800^{\circ} \mathrm{C}$ has shown percent strength loss to be $62.2 \%, 68.5 \%$, and $71.2 \%$ for the cooling regime hot state, water quenching and air cooling respectively, in case of HSC of M60 grade subjected to $800^{\circ} \mathrm{C}$ loss of strength obtained as $63.8 \%, 68.7 \%$, and $75.4 \%$ for the cooling regime hot state, water quenching and air cooling.

\subsection{Effect of Elevated Temperature on Hardness of the Surface of the Concrete}

In general the surface hardness as represented by the rebound number value in NDT indirectly represents the likely spalling or loosening of surface of concrete. The rebound number indicate that the rebound number values have decreased with elevated temperatures both normal and high strength concrete. This gives an indication that there may be increased risk of spalling in concretes with elevated temperature.

The NDT test results indicated more loss of hardness or increased risk of spalling was observed in case of HSC and $\mathrm{NC}$ at temperatures. This behaviour may be attributed to the high thermal incompatibility between different phases of materials in HSC. The hardness of surface as indicated by the rebound number was low for concrete specimens at hot condition; however there is an increase of rebound number of the concretes tested after water quenching and air cooling. This means water quenching and air cooling resulted in increase of surface hardness. The figures are shown in Figure 14, Figure 15 and Figure 16.

\subsection{Loss in Mass After Exposure to Elevated Temperatures}

The mass of the concrete cube before and after exposure to different cooling regimes at elevated temperatures were taken for mass loss evaluation. As the temperature increases, continuous increase in weight loss is observed. The air cooling and hot condition resulted in more percent loss of mass value compared to water quenching.

In case of normal concrete (M20) subjected to $800^{\circ} \mathrm{C}$ the percent loss in mass observed to be $3.3 \%, 3.8 \%$, and $4.2 \%$ for the cooling regime water quenching, air cooling and hot state and presented in Figure 17.

In case of normal concrete (M40) subjected to $800^{\circ} \mathrm{C}$ the percent loss in mass observed to be $3.6 \%, 4.5 \%$, and $5.2 \%$ for the cooling regime water quenching, air cooling and hot state and presented in Figure 18.

In case of high strength concrete (M60) subjected to $800^{\circ} \mathrm{C}$ 
the percent loss in mass observed to be $4.4 \%, 4.2 \%$, and $5.3 \%$ for the cooling regime water quenching, air cooling and hot state and presented in Figure 19.

\section{Conclusions}

In general the compressive strength of concrete is decreased, when the concrete is subjected to elevated temperatures.

The percentage decrease in strength, with elevated temperatures has increased with increase in grade of concrete i.e. higher strength concretes have higher percent loss in strength then lower strength concrete. However the difference becomes less significant at temperatures greater than $400^{\circ} \mathrm{C}$.

The decrease in compressive strength, with elevated temperature is more in case of HSC compared to NC. The rate of decrease in compressive strength is faster in the temperature range of $800^{\circ} \mathrm{C}$.

The rate of decrease in compressive strength is gradual in the range of $600^{\circ} \mathrm{C}$. The concrete retains its original strength up to a temperature of $400^{\circ} \mathrm{C}$ for M20 and M40.

After the testing of specimens' in three states i.e. in air cooling, water quenching and in hot state. Normally referred to as cooling regimes, more percentage of loss decrease in strength was observed for both normal and high strength concrete and testing after Water quenching resulted in higher loss in strength compared to the strength obtained in testing at hot condition.

Rebound number represents the hardness of surface and indirectly represents the likely spalling or loosening of surface concrete. The hardness of surface is low for the specimen at hot state, followed by the other states i.e. water quenching and Air Cooling. Finally it was concluded that there is more loss in hardness in case of HSC compared to NC at elevated temperatures.

\section{References}

[1] Saad M, Abo-EI-Enein S. A, Hanna G. B and Kolkata M. F Effect of temperature on physical and mechanical properties of concrete containing silica fume, cement and concrete Research, Vol. 26, No. 5, 669-675.

[2] Long T. Phan and Nicholas J. Carino; "fire performance of high strength concrete: research needs" ASCE, May 2000.

[3] Long T; "Spalling and mechanical properties of high strength concrete at high temperature" Environment and loading, 2007.
[4] Sujith Ghosh and Karim W. Nasser, Effects of high temperature and pressure on strength and elasticity of lignite fly ash and silica fume concrete, ACI Material Journal, February 1996.

[5] Material and environmental factors influencing the compressive strength of unsealed cement paste and concrete at high temperatures R. Sarshar; G. A. Ghoury Magazine of concrete Research, Volume 45, Issue 162, 01 March 1993.

[6] Castilo, C., Durrani, and AJ: Effect of transient high temperature on high strength concrete: ACI Mater J 1990; 35 (1): 47-53.

[7] V. Kodur and wasim khaliq, "effect of temperature on thermal properties of different types of high strength concrete" ASCE, $2011 \%$ Factors affecting fire Performance in high strength concrete.

[8] Effect elevated temperature on the properties of high strength concrete containing cement supplementary materials, R. Sri Ravindrarajah, R. Lopez and H. Reslan, $9^{\text {th }}$ international conference on durability of building materials and components, Brisbane, Australia, 17-20 ${ }^{\text {th }}$ march, 2002.

[9] Sri Ravindrarajah, R., residual compressive and tensile strength for high strength concrete exposed to high temperature up to $800^{\circ} \mathrm{C}$, proceedings internal conference on HPHSC, Perth, Australia, August 1998, 633-645.

[10] V. Kodur. And Nikhil Raut, "performance of concrete structures under fire hazard: emerging trends" ICI, 2010.

[11] Nassif, A. Y.; Rigden, S.; Burley, effects of rabid cooling by water quenching on the stiffness properties of fire damaged concrete. E-Source: Magazine of concrete Research, V 51, no 4, p 255-261, August 1999.

[12] K. Srinivasa Rao and M. Potha Raj "a study on variation of compressive strength of high Strength concrete at elevated temperatures" $25-26$ August 2004.

[13] O. Carvel, Asif Usmani and Stephen Welch, "Behaviour of concrete structures in fire".

[14] Kiran Kumar Poloju, Vineetha Anil, Ram Kishore Manchiryal, Impact of nano silica on strength and durability properties of self-compacting concrete, International Journal of Advanced and Applied Sciences, 4 (5) 2017, Pages: 120-126.

[15] Kiran Kumar Poloju, Ram Kishore Manchiryal, Chiranjeevi Rahul R, Development of sustainable concrete by using paper Industry waste, Elixir Civil Engg. 102 (2017) 44152-44154 44152.

[16] J Novak and A Kohoutková 2017 IOP Conf. Ser.: Mater. Sci. Eng. 246012045. 